\title{
Personnel Behaviour Management Through Social Communications
}

\author{
OLENA TKACHENKO ${ }^{1}$, IRYNA ZHYLENKO ${ }^{2}$, NATALIYA POPLAVSKA ${ }^{3}$, OLHA MITCHUK ${ }^{4}$, \\ HALYNA KUZMENKO ${ }^{5}$, VIKTORIYA ZOLYAK ${ }^{6}$ \\ ${ }^{1,2}$ Department of Journalism and Philology, SUMY STATE UNIVERSITY, UKRAINE. \\ ${ }^{3}$ Department of Journalism, TERNOPIL VOLODYMYR HNATIUK NATIONAL PEDAGOGICAL UNIVERSITY, UKRAINE. \\ ${ }^{4}$ Faculty of Journalism, ACADEMICIAN STEPAN DEMIANCHUK INTERNATIONAL UNIVERSITY OF ECONOMICS AND \\ HUMANITIES, UKRAINE. \\ ${ }^{5}$ Institute of Economic Development Studies, KYIV NATIONAL ECONOMIC UNIVERSITY NAMED AFTER VADYM \\ HETMAN, UKRAINE. E-mail: kuzmenko_h@meta.ua \\ ${ }^{6}$ Department of Social Communications, ACADEMICIAN STEPAN DEMIANCHUK INTERNATIONAL UNIVERSITY OF \\ ECONOMICS AND HUMANITIES, UKRAINE.
}

\begin{abstract}
Today is characterised by the formation and development of an open, civilised society; there are fundamentally new forms of communication-based on the social and personal partnership, competition, legal and social foundations of formal equality of all citizens, the rational regulation of social relations. The quantity and quality of communications are continually growing, a significant number of people are involved in the communication process, the relationship between individual communications becomes close, the action of communications whose network has reached a global scale is growing. Modern communication society is characterised by a constant increase and globalisation of communications. The consequence of this development of society is the extremely limited financial resources, significantly narrowing the range of measures and tools to improve the management of the organisation as a whole and its staff, in particular, on the one hand, and changes in the emotional and mental spheres of the employee. Therefore, in their study, the authors considered the concept of communication, types of communication, their impact on the management process of the organisation and identified the role and functions of social communications in personnel management. The authors studied and analysed the methods of personnel management in detail. Based on the theoretical and methodological analysis, the authors proposed a system for managing the behaviour of staff through social communications; proposed a matrix for the distribution of responsibilities and this system and proposed a method for evaluating its effectiveness.
\end{abstract}

Keywords: social communications, behaviour, efficiency, personnel.

JEL Classification: D22, D91, M12 


\section{Introduction.}

Fundamental changes in the economic, political, social life of the country urgently require leaders of various ranks to study modern methods and forms of managing organisations, raise questions related to understanding the role and place of a person in contemporary management models, behavioural orientations, and value preferences of a modern person (Shpak et al, 2018; Kolosok \& Biriukov, 2018). Any schools of modern management theory pay special attention to the person, the priority of the individual in the study of any social processes (Prokopenko, 2011; Tkachenko et al, 2020). The role of the human factor is significantly growing in the modern post-Soviet space since the Soviet system was characterised by an impersonal society, underestimation of the individual identity of a person and the inertia of pseudo-socialist thinking, which affects until now.

Each leader needs to take into account such features of modern reform as the extremely limited financial resources, which significantly narrows the range of measures and tools to improve the management of the organisation as a whole and its personnel, in particular, on the one hand, and the changes that have occurred in the emotional and mental spheres of the employee that require rapid development and the introduction of new management methods (Kuzmenko et al, 2019). The world order is changing too quickly to be predicted and adequately addressed, which complicates the use of various instruments (Shpak et al, 2018; Prokopenko et al, 2020). To ensure the stability of the organisation in the market, the manager must have employees who can approach work creatively, strive for innovations, develop cooperation with others, and achieve the optimal result. At the same time, a modern organisation is in need not just for a group of highly qualified specialists, but for a friendly, creative, self-adjusting team that can ensure a stable position of an economic organisation in the market and its internal stability not so much with personal decisions and instructions, but thanks to the optimal and effective use of what is in its disposal to the human resource. Experience shows that success is with those companies that focus on the perspective of labour management (Johnstone \& Wilkinson, 2017; Dunning \& Elliott, 2019). Successful organisations offer employees, in return for employment, the stability of remuneration, creation of conditions for expanding knowledge, improving skills, continuous self-improvement, empowerment, and career growth. This means a turn of management towards social technologies and communications, towards management through humanitarian means of influencing a person as the leading resource to increase the effectiveness of the organisation as a whole, taking into account the essential characteristics of the individual. These circumstances make it possible to define the current management activity as one of the most complex technologies contributing to the achievement of the organisation's chains, as well as an activity that combines such polar directions of development and impact as a rigorous analysis of financial sustainability and a humane attitude towards people working in the company, material stimulation and psychotechnology of management, etc. Thus, the main attention in the modern management of an organisation of any sectoral orientation should be paid to the management of its people culture.

\section{The role and functions of social communications in personnel management.}

Sociological research has shown that $73 \%$ of American, $63 \%$ of British and $80 \%$ of Japanese leaders believe that lack of communication is a significant obstacle to achieving their effectiveness (Petkun, 2016). Influential leaders are those who have succeeded in establishing communication and are themselves communicative. Communicability is the ability to communicate, develop contacts and connections, and achieve mutual understanding (WHO, 2017; Patel et al, 2011).

Several provisions namely evidences the importance and necessity of effective functioning of communications in the organisation:

1. Communication - the primary condition for the existence and development of the enterprise.

2. Communication interacts with the external environment, determining the level and quality of management decisions. 
3. Communications characterise the state of the internal environment of the organisation by ensuring the functioning and interaction of people, structure, goals, technology and objectives of the organisation.

4. Communication creates an informal structure in the process of functioning of the organisation and contributes to the rapprochement of the formal structure.

J. Lafta identified several points that should be primarily aimed at communication in the organisation:

1. Ensuring the effective exchange of information between objects and subjects of management, as well as between the organisation and its environment.

2. Improving interpersonal relationships in the process of information exchange.

3. Creating information channels for the exchange of information between individual employees and groups and coordination of their tasks and actions.

4. Regulation and rationalisation of information flows (Lafta, 2005).

Communications in management belong to the connecting processes of management, as they connect the functions of planning, organisation, motivation and control. The communication process is a process of exchanging information between two or more people (employees) to solve a problem. When considering the exchange of information in the enterprise, often mean people who communicate in person or a group at a meeting, talking on the phone or making notes, reports. And although these cases account for the bulk of communications in the enterprise, at the same time can not be limited to them in the analysis of a rather complex communication process.

Intra-organizational social communications should have several characteristics:

- $\quad$ be precise and accurate;

- transparent, and the information provided is based on reliable facts;

- should appeal to the best interests of people and help fight the atmosphere of mistrust in the collective.

Communication is considered successful if the recipient of the information understands its content adequately to the meaning that the sender put into it. The scheme of intra-organizational social communications is shown in Fig. 1.

Communications are the processes of communication of employees, departments, organisations and can occur in two planes (Fig. 2).

In addition to objective reasons, communication is hampered by subjective factors. For example, preconceived notions of people who reject new ideas because of their novelty, which seems dubious at first glance, or because of stereotypes. As a result, the perception of the message is distorted and, as a result, its effectiveness decreases, the feedback process slows down.

The effectiveness of communication can vary. According to foreign studies, the effectiveness of horizontal links reaches $90 \%$, vertical $-20-25 \%$ (this amount of information coming from managers reaches the workers and is correctly understood by them) (WHO, 2017; Prokopenko et al, 2020). In other words, performers can fulfil their functions with only a fifth of the information intended for them.

The lack of effectiveness of vertical (both upward and downward) communications is confirmed by the data that, for example, a financial director, leaving the office of the chief director, takes out only $30-40 \%$, the head of the sales department after a conversation with financial directors also 30 $40 \%$, i.e. in the most favourable scenario, the effectiveness of the initial message will be $16-20 \%-$ the fewer information transmission links there are, the better. Bottom-up communication is even more ineffective since no more than $10 \%$ of the information reaches the boss. This convincingly indicates that not all opportunities are used in organising communications. 
Figure 1. The movement of intra-organizational social communications



Figure 2. Types of communications of the organisation



It is also important to remember that the success of communication processes is organically linked to compliance with ethical standards both on the part of the recipient and the sender of information. The effectiveness of communications also depends on how the message is constructed. With its creation, it is necessary to observe a sequence of construction (Fig. 3).

Figure 3. Correct message construction sequence

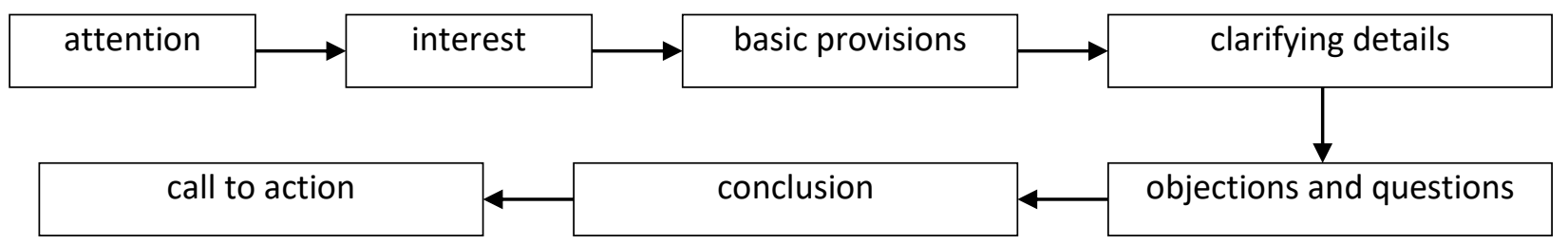

\section{Methods of personnel management.}

The attitude towards changes is based on the scale of human values: if the highest value for him is security and stability, then he will avoid any changes, if growth and development are vital to him, he will welcome them. According to the attitude of people to change, sociologists divide all people into groups (Overcoming Resistance to Change):
A. $2 \%$ - "resisting" (do not want to change anything)
B. $14 \%$ - "expectant" (afraid to make a mistake, require a proof)
C. $34 \%$ - "inert majority" (trying to identify errors and threats, require preliminary verification)
D. 34\% - "less inert majority" (trying to identify new opportunities, participate in the discussion) 
E. 14\% - "testers" (they like new ideas and perspectives; they are ready to try them, they buy not a "product", but a "promise", striving to be in the forefront)

F. $2 \%$ - "inventors by nature" (always think differently and want to change everything)

Depending on which group the employees belong to, the motivation for joining the transformation will be different for them. The methods of overcoming resistance for them will also be different.

$16 \%$ of people $(E, F)$ are innovators. It is useful when the implementation team consists of such people - this guarantees the success of the transformation. The motivation for innovators is "we did it", "we are the first".

34\% (D) are inert, value stability and permanence, but do not mind using new opportunities. These employees need to demonstrate the benefits and new opportunities they will receive from the innovation. Maybe for some, it will be a new position or a new job. For this group, first of all, personal perspectives are important.

$34 \%$ (C) are inert, cautious, afraid that it will get worse, as well as for group D; they are primarily interested in the impact of changes on them personally. For this group of employees, it is necessary to show that nothing will fundamentally change in their lives: salary, boss, responsibilities - in general, everything will be the same as now, some details will change. In a calm state, these employees will follow Group D, seeing that nothing happens to them and accepting all changes after them.

14\% (B) - until recently, they will consider all changes to be a mistake and a bad idea. As a rule, such employees do not actively influence the course of changes. But they mustn't be on the implementation team. One such employee in the group is able to stop the whole process.

2\% (A) are militant retrogrades. Even when everything has already happened, they will be nostalgic for the old days. It is essential to know these employees in your company. It is best to send them on vacation during the changes to avoid their destructive influence.

The practical essence of social communications lies in the ability to influence a person by word, create a favourable moral and psychological atmosphere in the team, relieve emotional tension, and assist in improving the personality of an employee.

Motivation. One of the main tasks of the implementation team is to find benefits from the changes for literally every employee who will be affected by these changes. The manager needs to be clearly aware that change is stressful for employees, and only the right motivation can help to read it. The nature of this motivation depends on which of the groups of attitudes toward change the employee belongs to.

Informing. Often, in the process of change, the role of information is greatly underestimated. Management has to see how a team of revolutionaries develops something for a long time; then everyone is told that they need to live in a new way. This is a wrong tactic, most often, it leads to all kinds of losses.

The organisational system is a community of people. The work of the "Revolutionary Group" will be known almost instantly. And in the absence of official information about his work, he will be replaced by speculation and rumours that will not be positive at all. People, in general, tend to prepare for the worst, especially in our country. As a result, when changes are announced, they will already have a negative image, and the inactive majority will already be against the change.

It is not necessary to talk about all the details, but we need to convey the idea that change will be positive and beneficial - it will help cope with resistance to change in the future.

\section{Creation of a program for managing the behaviour of personnel through social communications.}

The development of a program for managing personnel behaviour through social communications should begin with an overall assessment of the management environment. Then study the 
organisational structure and the type of existing communications. To assess the current state of the team and the degree of employee satisfaction is necessary to conduct a little internal research and establish what forms of communication, employees consider the most appropriate and effective. The results of the check will show whether it is already possible to introduce new types of communications in the organisation or reveal some difficulties and tension in the team.

Suggestion boxes and general meetings are two of the most common ways to communicate between employees and management. But they become ineffective if suggestions from employees do not find an answer. This often happens since there are quite a few messages, and it is not possible to answer all of them. Sometimes the management of an enterprise is formally related to the very idea of boxes and does not bother with answers. For these methods to be effective, you should initiate group (team) proposals, which significantly simplifies the procedure for replies. It is also important not to turn general meetings into a farce: the dialogue of opponents should not develop into a monologue of one person. Do not force employees to attend and sit out such meetings. Notes sent to the rostrum must not be censored.

Any issue must be approached systematically; this will provide a synergistic effect and increase efficiency; therefore, we propose to approach the issue of personnel management using social communications as a system formation (Fig. 4).

Figure 4. Formatting the social communication system to manage the personnel



The analysis and correction of the system complete only the process of content filling, but the work on their organisational consolidation is not completed. Distribution of responsibility and 
authority of the management personnel involved in the process of providing (formation, maintenance or improvement) of the organisation's system is one of the essential stages (Table 1).

This matrix is not immutable, but it is typical because it allows you to understand the address of specific tasks related to social communications in the organisational structure of the organisation. In the absence of any of the units or their unpredictability in the budget - the task can be performed with their resources or combined with jobs.

\section{Evaluation of the effectiveness of the Personnel Behavior Management System through social communications.}

We propose to evaluate the effectiveness of the System through the achievement of sub-goals, which in the organisation may be the following:

- reducing staff turnover;

- reduction of violations of labour discipline;

- increasing employee loyalty to the organisation;

- formation of a friendly atmosphere in the team;

- increasing employee motivation;

- decrease in absences due to illness;

- increase in cases of constructive criticism, etc.

It is also necessary to assess the effect of the communication message, taking into account the dual nature of the effect of the communication impact on employees. In general, efficiency is calculated:

$$
\text { Efficiency }=\text { Effect } / \text { Cost }
$$

The effect function $(E)$ has the form:

$$
E=f(N, K V, R, C S)
$$

where $N$ - the number of communication carriers, units;

$K V$ - coefficient that eliminates the consideration of the carrier;

$R$ - the number of installed feedback effects, units;

CS - coefficient of taking into account the impact of the message on the recipient, which is not economic in nature (in particular, psychological, environmental, etc.).

Adhering to the above logic of factors of economic $(P)$ and motivational $(R S)$ effects, and at the same time integrating logical and methodological preconditions, we can say that in the number system RS forms a probabilistic weighting factor concerning the expressed economic effect. This is where their logical functional relationship according to the basic methodology, is manifested.

Since the motivating factor is weight, i.e. logically probabilistic, the assessment of the effectiveness of social communications can be reduced to the following functional dependence:

$$
E^{\wedge} p=f(P \times P S)
$$

where $E p$ - the effect of social communications, expressed through the probability of obtaining a positive result, UAH;

$P$ - economic factor of efficiency of social communications, UAH;

$P S$ - motivating factor for the effectiveness of social communications, UAH.

Since for the factor $P$ it is possible to quantify the result of communication interaction, the effect taking into account the RS also numerically reflects with a certain probability the intermediate economic factor. Thus, the meaning of the economic factor is revealed in the model; its numerical 
expression should be determined not by the final results of economic activity, but on the basis of fixing the boundary values between the activity and the communication process by the system of primary contacts.

Table 1. Matrix of distribution of responsibilities and powers of management personnel involved in the process of formation, maintenance or improvement of social communications of the enterprise

\section{Components of the program of personnel behaviour management through social communications}

\section{Analysis, systematisation and generalisation of information}

2. Defining the goals of the enterprise

3. Defining the social and communication goals of the enterprise

4. Determining the budget of the SC

5. Formation of the SC

6. Selection of SC distribution channels

7. Informing the workers of the enterprise

8. Getting feedback

9. Analysis of the reaction of workers

10. Analysis of the effectiveness of the SC

\section{Adjustment of the SC}

Symbols: $\square$-initiates, manages, controls; $\square$-participates; $\square$-responsible for implementation.

The main purpose of the IC, as well as the purpose of all activities of the enterprise, is to achieve the socio-economic effect. The latter is achieved if there is a motivational effect provided by highquality rational social communications of the first stages of impact on staff.

The factor weighted model reflects the magnitude of the motivating factor for the effectiveness of social communications. In it, the importance of factors and assessment of the current state of elements is determined and determined for a certain period to check the communication activity of the enterprise.

Conventional weight factor models interpret the statistical array of weighting factors as a weighted value about the estimation of the factor. Therefore, the essence of the position of the factor RS can be expressed by the ratio of arrays: 


$$
P S_{k n}=\sum\left(W_{k n} \times A_{k n}\right)=\left|\begin{array}{l}
W_{1} \\
\ldots \\
W_{m}
\end{array}\right| \times\left|\begin{array}{c}
A_{1} \\
\ldots \\
A_{m}
\end{array}\right|
$$

The essence of the integration efficiency indicator reflects its manifestation by functional dependence:

$$
E=f(P S, \triangle N, K V)
$$

Since RS and $\Delta N$ are the probabilistic values of the weighing model, there is a similarity between the expression of the economic effect and the complex integration effect of all social communications. The reflection of the impact is based on the number of potential consumers, which means that efficiency, as a holistic change, determines the objective possibility of selling $\Delta \mathrm{N}$ the number of consumers of products. This identity becomes more relevant because the result of economic (communicative, marketing) activities of the enterprise involves achieving the effect of selling the maximum number of products to potential consumers $\Delta \mathrm{N}$, expressed in $\mathrm{Q}$.

Thus, the integral efficiency can be expressed through the probability series:

$$
E=\rho^{\wedge}(K V, P S) \times \Delta N
$$

where $\rho K V, P S$ is the probability function $P S$ and $\Delta N$.

You should also receive and analyse feedback and focus on exploring the achievement of the company's goals. The stage involves the development of a questionnaire to interview the views of employees on the social and communication activities of the organisation, which should be used after a particular stage or the implementation of the entire System.

\section{Conclusion.}

Given the impossibility of effective functioning of the communication system without proper management, managers and managers of the enterprise to form quality communication systems need to improve the management mechanism based on goal setting and management of social communications. To enhance communication in the management process at the enterprise it is necessary to clearly define the need for information of each structural unit and each workplace, to regulate information flows in accordance with the tasks; there should be an interaction between managers and subordinates; organisation of an effective feedback system; introduction of a system for collecting proposals; information messages of the enterprise administration; use of modern information technologies. Top managers must constantly give management activities a more organised nature: to improve the planning of mass organisational events, meetings, conferences, meetings with subordinates, managers of other enterprises.

\section{References}

1. Dunning, G., \& Elliott, T. (2019), "Hard Labour: Managing a Problematic Workload", Making Sense of Problems in Primary Headship. Emerald Publishing Limited, pp. 47-62. DOI: 10.1108/978-178973-903-920191007

2. Johnstone, S., \& Wilkinson, A. (2017). The Potential of Labour-Management Partnership: A Longitudinal Case Analysis: Potential of Labour-Management Partnership. British Journal of Management, 29(3), DOI: 10.1111/1467-8551.12240

3. Kolosok, V., \& Biriukov, M. (2018). Management models of the integrated enterprise's logistics system of the holding company, Reporter of the priazovskyi state technical university. Section Economic Sciences, 1(36), pp. 200-204 DOI: 10.31498/2225-6725.36.2018.169243

4. Kuzmenko, H. et al. (2019). The experimental model of procurement in public administration. International Journal of Innovative Technology and Exploring Engineering, 8(11), pp. 2773-2778. 
5. Lafta, J. (2005). Management: teach. manual. Moscow: T.K. Welbee, 592 pp.

6. Overcoming Resistance to Change. https://sudonull.com/post/84615-Overcoming-Resistance-toChange

7. Patel, F., Mingsheng, L., Sooknanan, P. (2011). Intercultural communication: Building a global community. SAGE Publications India Pvt Ltd, DOI: 10.4135/9781446270318

8. Petkun S. (2016). Communication in the enterprise management process. Economy. Management. Business, 3 (17), pp. 24-31.

9. Prokopenko, O. Kazanska, O., Deineha, I., Butenko, N., Omelyanenko, V., \& Bovkun, O. (2020). Communication business processes of industrial enterprises in the conditions of globalisation. International Journal of Management, 11(5), pp. 884-895.

10.Prokopenko, O.V. (2011). Consumer choice types in marketing of ecological innovations. Actual Problems of Economics, 16(2), pp. 109-116.

11.Shpak, N.O., Stanasiuk, N.S., Hlushko, O.V., \& Sroka, W. (2018). Assessment of the social and labor components of industrial potential in the context of corporate social responsibility. Polish Journal of Management Studies, 17 (1), pp. 209-220. DOI: 10.17512/pjms.2018.17.1.17.

12.Tkachenko, O., Yanenko, Y., Sydorenko, O., Sypchenko, I., Dudchenko, L., \& Rudenko, N. (2020). Marketing communications in election campaigns. International Journal of Advanced Research in Engineering and Technology, 11(6), pp. 525-533.

13.WHO Strategic Communications Framework for effective communications. (2017). World Health Organization, https://www.who.int/mediacentre/communication-framework.pdf 